\title{
26. Variation of Optic Axial Angle through Zero
}

\author{
By Seitarô TsuboI, M.J.A. \\ Geological Institute, Faculty of Science, University of Tokyo
}

(Comm. March 12, 1962)

As is well known, the optic axial angle of a biaxial crystal varies with the change of temperature at which the crystal is kept, or with the change of colour (wave-length) of light used in observation. Similar variation in the optic axial angle is also seen in solid solution series, with the change in chemical composition.

In some cases of the variation as above, the value of the optic axial angle passes through zero. For example, in sanidine from the Eifel (S. Kôzu and K. Seto, 1921), the optic axial angle in the plane normal to 010 for yellow light (wave-length $\lambda_{0}=589.3 \mathrm{~m} \mu$ ) grows smaller on heating, becomes zero at $43.5^{\circ} \mathrm{C}$, and opens again in the plane parallel to 010 ; while at $43.5^{\circ} \mathrm{C}$, the optic axial angle varies with the change of colour of light from violet to red through zero for yellow light, accompanying the change in the optic axial plane from 010 to the plane normal to it. Variation of the optic axial angle through zero with the change in chemical composition of solid solution series is exemplified by clinopyroxene series, $\mathrm{MgSiO}_{3}-\mathrm{CaMgSi}_{2} \mathrm{O}_{6}$ (N. L. Bowen, 1914; A. N. Winchell, 1923) and $\mathrm{MgSiO}_{3}-\mathrm{CaFeSi}_{2} \mathrm{O}_{6}$ (A. N. Winchell, 1923).

The relation between the optic axial angle $(2 \mathrm{~V})$ and the factor influencing thereto $(x)$, viz., temperature or wave-length of light or chemical composition, may be graphically represented by plotting the former as ordinate and the latter as abscissa. Diagrams constructed in that way are common in literature. Some of them, however, are not correctly drawn. Especially it is to be remarked that in some (for example, Winchell's diagrams of clinopyroxene series, $\mathrm{MgSiO}_{3}-\mathrm{CaMgSi}_{2} \mathrm{O}_{6}$ and $\left.\mathrm{MgSiO}_{3}-\mathrm{CaFeSi}_{2} \mathrm{O}_{6}, 1923\right)$ the variation curve of $2 \mathrm{~V}$ through zero is erroneously drawn so that it cuts obliquely the line for $2 V=0^{\circ}$. The curve should cut perpendicularly the line for $2 V=0^{\circ}$. It is the purpose of this paper to show what has been just said.* A proof of this is given below:

The relation between $2 V$ and $x$ in cases where $2 V$ varies through

* That the variation curve of $2 \mathrm{~V}$ through zero should cut perpendicularly the line for $2 V=0^{\circ}$ has been shown by the present writer (S. Tsuboi, 1959) in his book in Japanese language, "Henkô-Kenbikyô (Polarizing Microscope)". It is repeated here in English for foreign readers, to many of whom the Japanese text may not be easily accessible, in view of the necessity of this presentation as preliminary to the discussion in the next paper. 

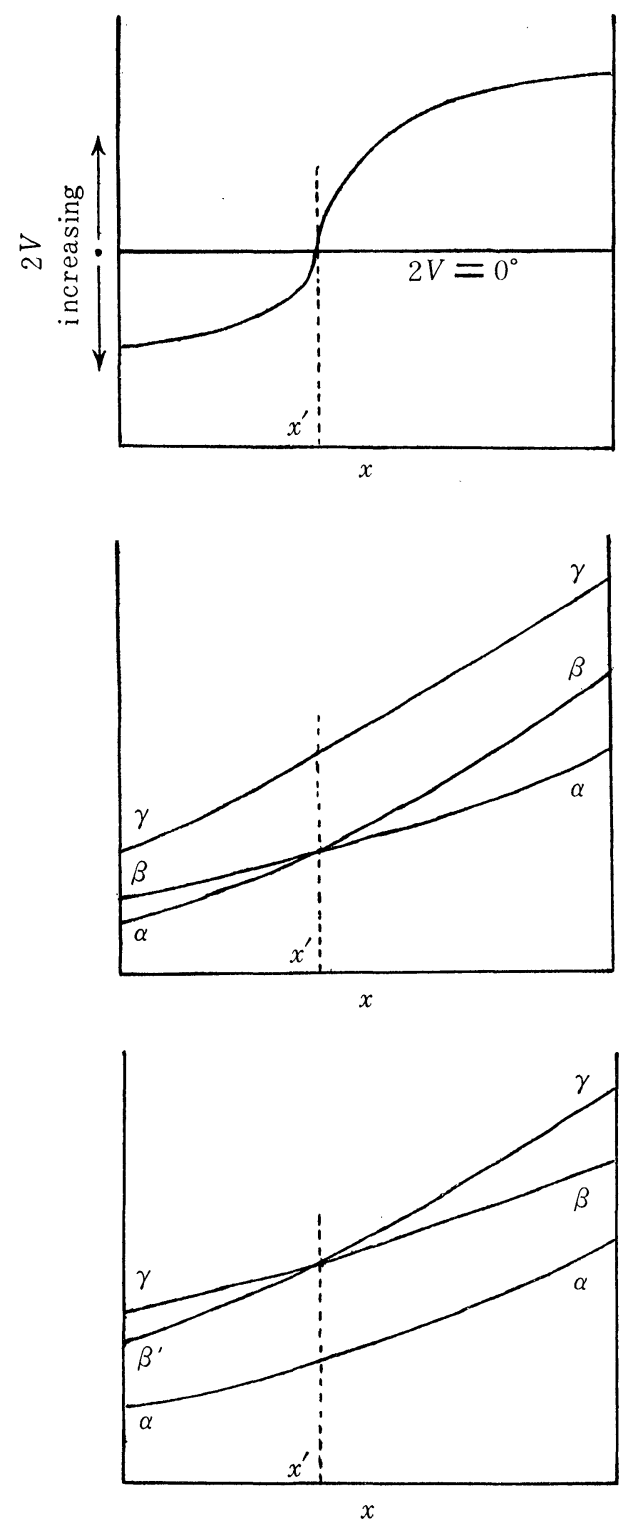

Fig. 1. Variation of $2 \mathrm{~V}$ through $0^{\circ}$. $2 \mathrm{~V}$ increases both upward and downward from the line for $2 V=0^{\circ}$, respectively with an optic axial plane, perpendicular to each other.

Fig. 2. A case of variation of $\alpha, \beta$, and $\gamma$, accompanying variation of $2 \mathrm{~V}$ through $0^{\circ}$. Uniaxiality occurs where $\alpha=\beta$.

Fig. 3. A case of variation of $\alpha, \beta$, and $\gamma$, accompanying variation of $2 \mathrm{~V}$ through $0^{\circ}$. Uniaxiality occurs where $\beta \doteq \gamma$.

zero is illustrated in a general manner by Fig. 1 . The variation of $2 \mathrm{~V}$ as this is accompanied by the variation of the principal refractive indices, $\alpha, \beta$, and $\gamma$, as shown either in Fig. 2 or in Fig. 3. The uniaxiality $\left(2 V=0^{\circ}\right)$ occurs at abscissa $x^{\prime}$, where the curves of $\alpha$ and $\beta$, or the curves of $\beta$ and $\gamma$, meet each other (i.e., at the point corresponding to $\alpha=\beta$ in Fig. 2 , or $\beta=\gamma$ in Fig. 3).

Taking the case of Fig. 2, let the $\beta$ - $\alpha$ curve (i.e., the curve that represents $\beta$ on the left side of $x^{\prime}$, and $\alpha$ on the right side of $x^{\prime}$ ) be denoted by $f_{1}(x)$, and the $\alpha-\beta$ curve by $f_{2}(x)$, both being functions 
of $x . \quad V$ is also a function of $x$; and the value of $V$ becomes zero at $x^{\prime}$, where $f_{1}(x)=f_{2}(x)$.

From the well known relation

$$
\sin V=\frac{\gamma}{\beta} \sqrt{\frac{(\beta+\alpha)(\beta-\alpha)}{(\gamma+\alpha)(\gamma-\alpha)}}
$$

it follows that

$$
\cos V\left(\frac{d V}{d x}\right)=\frac{d}{d x}\left(\frac{\gamma}{\beta} \sqrt{\frac{(\beta+\alpha)(\beta-\alpha)}{(\gamma+\alpha)(\gamma-\alpha)}}\right)
$$

and $\frac{d V}{d x}$ at $x^{\prime}$ is obtained as

$$
\left(\frac{d V}{d x}\right)_{x=x^{\prime}}=\frac{\gamma}{\beta}\left(\frac{f_{1}\left(x^{\prime}\right)}{\sqrt{(\gamma+\alpha)(\gamma-\alpha)}} \cdot \frac{f_{2}^{\prime}\left(x^{\prime}\right)-f_{1}^{\prime}\left(x^{\prime}\right)}{\sqrt{(\beta+\alpha)(\beta-\alpha)}}\right)_{\alpha=\beta} .
$$

Here

$$
f_{2}^{\prime}\left(x^{\prime}\right)-f_{1}^{\prime}\left(x^{\prime}\right)>0 \text {, }
$$

therefore

$$
\left(\frac{d V}{d x}\right)_{x=x^{\prime}}=+\infty \text {. }
$$

This shows that, in the case of Fig. 2, the curve of $2 V$ cuts perpendicularly the line for $2 V=0^{\circ}$.

A similar proof applies in the case of Fig. 3.

\section{References}

N. L. Bowen (1914): The ternary system: diopside-forsterite-silica, Amer. Jour. Sci., 38, 207-264.

S. Kôzu and K. Seto (1921): Sanidine from the Eifel, Science Reports of Tôhoku Imp. Univ., Ser. III, 1, 25-32.

S. Tsuboi (1959): Henkô-Kenbikyô (Polarizing Microscope), in Japanese, 105-107 and 253-255.

A. N. Winchell (1923): Studies in the pyroxene group, Amer. Jour. Sci., 6, 513 and 514 . 